\title{
HACIA UNA ÉTICA GLOBAL
}

Fernando Lolas Stepke

Desde que Acta Bioethica fuera incorporada a los principales sistemas internacionales de registro de publicaciones periódicas y su impacto creciera, en comparación con revistas semejantes, la cantidad de manuscritos no solicitados ha significado una formidable tarea tanto para los pares evaluadores como para el comité editorial internacional. También ha significado que el carácter monográfico que siempre ha caracterizado a la publicación sea difícil de mantener. Súmese a eso el trilingualismo (español, portugués, inglés) y se tendrá una medida aproximada de la complejidad que significa hoy publicar Acta Bioethica.

La amplitud de los temas tratados en esta fase de expansión queda bien reflejada en este número. Ya comienza a responder a una diversificación temática que ha sido objeto de un subsidio especial de la Comisión Nacional de Investigación Científica y Tecnológica (CONICYT) de Chile, que permitirá, a partir de la segunda mitad del año 2013, perfeccionar el sitio web y mejorar la gestión editorial en los idiomas de publicación.

Asimismo, una interrelación más estrecha con el Instituto de Estudios Internacionales de la Universidad de Chile permite al Centro Interdisciplinario de Estudios en Bioética (CIEB), responsable de la publicación, una mejor expansión hacia temáticas que se alejan del sesgo sustantivamente biomédico que caracteriza a algunas publicaciones que aparecen con la rúbrica "bioética" en su título. Como no todas estas publicaciones son de valor intelectual relevante, la misma palabra corre hoy peligro de ver desvirtuado su sentido amplio, abarcador e integrador que sus creadores, Fritz Jahr y Van Rensselaer Potter, quisieron darle.

La mantención de un sistema de revisión por pares, la revisión escrupulosa de estilo y la amplitud temática son fortalezas que persisten. En esta entrega se incluyen, además de los trabajos estructurados según las normas editoriales y las recensiones y comentarios de publicaciones, breves notas descriptivas de encuentros internacionales. Si bien este tipo de materiales no suele ser citado y carece por ello de la entidad de los trabajos citables (responsables del impacto), hemos decidido, bajo cierta norma de brevedad y parsimonia, incluirlo cuando esté disponible y los organizadores de encuentros lo provean. Así, la sección "Colectánea" permite la reconstrucción del devenir de un discurso que aún no encuentra la solidez de las disciplinas sustantivas, pero permitirá a quienes la revisen observar sus dimensiones personales, tan íntimamente ligadas al cultivo de la bioética, especialmente en América Latina. Región ésta que sigue apegada a ciertos rituales pseudoacadémicos en esta área y en la cual, como era de esperar, florecen las formas más pintorescas de interpretación y autobombo.

Los trabajos aquí presentados, como se indica más arriba, dan la idea de una expansión temática esperable y necesaria. Si escogemos la designación "ética global" para agruparlos es para dar la impresión de la diversidad de aspectos. Lo cual, aunado a la internacionalización de los autores, significa una cierta transformación, aún modesta, de lo que ha venido llamándose bioética.

Junto con agradecer a los autores, a los miembros del comité editorial y en especial a Álvaro Quezada e Isabel Cornejo Plaza (editora invitada en esta ocasión) la labor integrada que significa Acta Bioethica, confiamos que la lectura de este número estimulará a muchas personas a proseguir por el difícil camino 
Hacia una ética global - Fernando Lolas Stepke

de la solvencia intelectual y que estos trabajos servirán de inspiración para investigaciones necesarias. También debe agradecerse a Francisco León su preocupación por mantener al día la presentación de nuevos textos. Esperamos que la relevancia de la revista, ya superada la etapa de consolidación, se vea incrementada en la gestación de un discurso amplio y — precisamente- global. 